\title{
Criterion score of the physical and psychophysiological condition of students in the context of determining their individual adaptability to physical loads
}

\author{
Yagotin R. S. ${ }^{1 \mathrm{ABCDE}}$, Degtyarenko T. V. ${ }^{2 \mathrm{ABCDE}}$, Bosenko A. I. ${ }^{2 \mathrm{ABCDE}}$, Plisko V. I. ${ }^{3 \mathrm{ADE}}$, Dolinsky B. T. ${ }^{2 \mathrm{CDE}}$ \\ ${ }^{1}$ Department of Physical Culture and Sport, Odessa National Academy of Food Technology, Ukraine \\ ${ }^{2}$ Department of Biology and Public Health, South Ukrainian National Pedagogical University named after K. D. \\ Ushynsky, Ukraine \\ ${ }^{3}$ Department of Pedagogy, Psychology and Methods of Physical Education, National University of «Chernihiv \\ Collegium» Taras Shevchenko, Ukraine
}

Authors' Contribution: A - Study design; B - Data collection; C - Statistical analysis; D - Manuscript Preparation; E - Funds Collection.

\begin{tabular}{|c|c|}
\hline \multicolumn{2}{|l|}{ Abstract } \\
\hline Purpose: & $\begin{array}{l}\text { to suggest and to evaluate the criterion score of the physical and psychophysiological condition of students. } \\
\text { The basis of the score is the individual-directed pedagogical control at physical education. }\end{array}$ \\
\hline Material: & $\begin{array}{l}\text { the study involved students ( } \mathrm{n}=75 \text {, age }-17-19 \text { years). The physical condition was determined by applying } \\
\text { anthropometry and motor skills testing. The psychophysiological condition was studied according to } \\
\text { objective parameters of psychomotor qualities and functional capabilities of the cardio-respiratory system. }\end{array}$ \\
\hline Results: & $\begin{array}{l}\text { It was realized the criterion score of the individual degree of students' adaptability to physical loads. It was } \\
\text { determined the most significant interrelation between the indicators of motor qualities and psychomotor } \\
\text { parameters of students. It was revealed the approaches of realization the complex individual-directed } \\
\text { pedagogical control in the physical education of students. }\end{array}$ \\
\hline Conclusions: & $\begin{array}{l}\text { criteria of physical and psychophysiological capabilities of students are recommended for determining their } \\
\text { adaptability to physical loads. }\end{array}$ \\
\hline & criterion score, adaptability, physical education, psychomotor system, students. \\
\hline
\end{tabular}

\section{Introduction}

The definition of adaptive abilities of the individual considering his age, gender, and psychophysiological peculiarities is the actual and perspective direction of pedagogical science. The abovementioned is crucial for the organization of physical education and sports classes according to the modern requirements [1,2]. It is expedient to reveal the neurophysiological and psychophysiological mechanisms of adapting the organism to various factors of the external environment [3]. The development of this scientific direction was carried out in the context of determining the adaptation of the individual to physical loads of different orientations [4]. According to various data, the condition of health of young people has significantly deteriorated in recent years [5-7]. It is noted that among students there is a small proportion of practically healthy persons [8-10]. The introduction of health diagnostic methods according to objective parameters of physical and psychophysiological condition was confirmed in the studies of various authors [11-13]. Il'in [11] emphasizes the continuity of the physical and psycho-physiological component in the organization of human loads. Nikandrov [6], Degtiarenko et al. [7] suggest the application of psychomotor tests as a priority for evaluation of the adaptability of the individual.

A lot of authors emphasize the feasibility study of the interdependence of the functional condition and the

\footnotetext{
(c) Yagotin R. S., Degtyarenko T. V., Bosenko A. I. , Plisko V. I. , Dolinsky

B. T., 2019
}

doi:10.15561/20755279.2019.0108 volume of motor loads of students [14-16]. It is proposed to determine the functional level of students on the performance of cardiovascular and respiratory systems. The criteria for adaptation are arterial pressure, heart rate at rest, the vital capacity of the lungs (VCL) and Stanger test $[17,18]$. In the process of physical education, there should be performed the complex coordination abilities testing [19]. It is determined the importance of studying power, speed qualities and flexibility in the pedagogical control of the physical education process of students [20, 21]. Sergiienko defines the need to consider the somatotype of students during physical education modeling [22]. It is determined the peculiarities of the development problem individualization in the framework of the psychophysiological paradigm's implementation. It is revealed the high level of correlation between the perceptivecognitive indicators and psychomotor functions of a person [23]. The necessity of psychomotor qualities research for determining the level of a person's physical development is confirmed in the study of Tarovyket al. [24]. The development of quantitative and qualitative scales to determine the psychophysiological rating of respondents is revealed in the study of Korobejnikov et al. [25]. The comprehensive evaluation of physical fitness and psychophysical status of students of the special medical group is presented in the study of Blavt [16]. It is proved that the intensification of the test process ensures the effectiveness of the implementation of the diagnostic control function of physical education [27-29].

Everyone is able to adapt to constant changes in the 
natural and social environment. This requires continuous improvement of personal adaptation resources [4, 21]. It is important to consider the main theoretical and methodological provisions of the medical and pedagogical control of physical education. It is necessary to define the interdisciplinary sense of such a concept as "adaptation". The phenomenological sense of the adaptation process should be considered in the system "man - environment". It is important to determine the degree of adaptability of the individual to a particular type of loads. The result of such loads is the success or failure of various tasks. For example, the effectiveness of mastering certain types of physical exercises [30]. It is necessary to emphasize the necessity of experts' compliance in the interpretation of the terminological definition "adaptation" and "adaptability of the individual". It is necessary to adhere to the terminology discipline in defining and interpreting the abovementioned concepts. The terms "adaptability or disadaptability" are used in the context of evaluating the effectiveness of different activities. It will be legitimate to use these concepts in determining the success or failure of physical exercise [3, 13].

The actual problem is the implementation of an individual approach to the educational process organization. This principle should be based on the objective evaluation of the adaptability degree of students to mental and physical loads.

Hypothesis. The study of individual characteristics of the physical and psychophysiological condition of students should be conducted on the basis of objective criteria. It provides an opportunity to determine their adaptability to physical loads. Such an approach will allow the implementation of individual pedagogical control in physical education.

The purpose of the work is to offer and test a criterion evaluation of the physical and psychophysiological condition of students. The basis of evaluation is the individual-directed pedagogical control of physical education.

\section{Material and methods}

Participants. The students participated in complex research ( $\mathrm{n}=75$, age $-17-19$ years). The mandatory condition for participation in the study was a medical examination and the absence of contraindications to physical education. All students give written consent for participation in the research.

Design of the research. The research was conducted during 2017-2018. Complex researches of diagnosticprognostic direction were performed according to the developed author's program [1]. The program included an individualized evaluation of the physical and psychophysiological condition of students according to objective parameters $[11,12]$. The developed and implemented program included the following stages:

I. General data (age, gender, medical background).

II Physical condition (anthropometry and motor quality).

III Psychophysiological condition (psychomotor quality).

IV Functional abilities (the potential of the cardiorespiratory system).

Analysis of anthropometric data and motor qualities indicators of student allowed to determine the peculiarities of each student's physical condition [22, 31, 32]. The following indicators were determined: body length $(\mathrm{cm})$; body weight $(\mathrm{kg})$; chest circumference at rest $(\mathrm{cm})$; dynamometry strength $(\mathrm{kg})$. Individualized evaluation of students' motor skills was performed applying the following tests: $100 \mathrm{~m}$ run (s); 4x9 m shuttle run (s); pushups (times); sit-ups in sitting position in 1 min (times); standing jump from the spot $(\mathrm{cm})$; forward inclination of body from sitting position (cm) $[21,33,34]$. It was applied the following criteria for evaluating the students' physical condition: body mass index (BMI); Power index (PI); Index Pynie (IP) [35]; speed of running; Coordination; Power endurance; speed power; Flexibility [22, 30, 36]. In our opinion, these criteria should be considered acceptable for the application in professional loads of physical education teachers. Such criteria are informative, accessible, safe and valid.

The psychophysiological studies were performed to determine the individual peculiarities of the psychomotor system and functional abilities of the body. They allowed to study the condition of perceptive-cognitive function and student psychomotor system. It was determined the parameters of sensorimotor components of motor loads and the students' cardiorespiratory system potential (CRS). Individualized evaluation of students' psychophysiological condition is calculated by the computer program (NS-Psychotetest) [37]. We have chosen 5 directions: "Visual sensorimotor reactions" (simple and complex), "Reaction to moving object", "Tap test", "Kohs Block Design Test" [37, 38]. Testing of individual features of the cardiovascular and respiratory systems allowed to determine their functional capabilities. It was determined the heart rate, timed inspiratory capacity and timed expiratory capacity [35]. Individual peculiarities of the psychomotor system and functional abilities of students were determined according to the following criteria: duration of the latent period of choice reaction; level of sensorimotor excitation; level of sensorimotor accuracy; the speed of a dominant hand; coefficient of functional asymmetry; Loads of thinking; potential of CRS.

Determination of students' adaptability to physical loads was performed at the following stages:

1. Diagnostic - physical and psychophysiological condition testing.

2. Selection of criteria - according to anthropometric data, motor qualities, the psychomotor system condition and functional abilities [1,22].

3. Development of a quantitative and qualitative scale - based on the average values of the selected criteria (for transformation the obtained results into the score) $[19,39$, 40].

4. Calculation of total points - according to the results of each test. 
5. Integrative evaluation of adaptability - according to the appropriate degree (high; significant; insignificant; disadaptation) [41].

6. Analytical interpretation of the distribution of students by the degree of adaptability to physical loads

The results of the testing were given the following score: 1 - failing, 2 - unsatisfactory, 3 - satisfactory, 4 good, 5 - excellent. The next stage was to implement the interpretation of the total score to determine the students' adaptability degree to physical loads. Criterion-point evaluation of students' adaptability to physical loads was the following: high $-80-61$ points; significant - 60-41 points; insignificant degree $-40-21$ points; disadaptation 20 points and less [38]. The proposed criterion evaluation allowed to determine the students' adaptability degree to physical loads and to divide the examined contingent into the appropriate groups.

Statistical analysis: SPSS20 and Excel programs were applied. The following indicators were calculated for each variable: average mean, standard deviation, mean error, the coefficient of variation. The level of correlations between the selected adaptation criteria was determined by correlation analysis.

\section{Results}

The results of the conducted research allowed to offer an individualized criterion evaluation of the physical and psychophysiological condition. The average means of the selected criteria of the physical and students' psychophysiological condition evaluation are presented in Table 1.

The percentage division of students into the degree of adaptability to physical loads $(n=75)$ is presented in Figure 1.

The "high" degree of adaptability to physical loads was found in $11.2 \%$ of students. "Sufficient" adaptability is determined in $26.6 \%$ of students. The most widespread evaluation of the studied contingent was "insignificant" adaptability to physical loads. It was detected in 33 students (44.1\%). Disadaptation to physical loads is determined in 14 students. More than $18 \%$ of students were characterized as unable to perform the educational loads in physical education. Only $38 \%$ of students can engage in physical education without risk to health ("adapted"). The obtained data became the basis for the correction of educational programs for the students' physical education belonging to the group "unadapted".

The carried out correlation analysis allowed to determine the most significant correlations between the indicators of motor qualities and the parameters of the psychomotor system. It is determined the significant correlation are between the duration of the latent period of choice reaction and coordination $(r=0.412)$; duration of the latent period of choice reaction and speed of running $(\mathrm{r}=0.393, \mathrm{p}<0.01)$; potential of the cardiorespiratory system and power endurance $(r=0.427, p<0.01)$.

\section{Discussion}

We consider the psychophysical abilities of a person in performing motor actions as his individualized characteristics. The motor actions qualities reflect the unity of neurophysiological and psychological mechanisms of a person's motor loads $[11,12]$. Parameters of simple motor actions are well measurable $[23,37]$. The evaluation of the functional capacity of the cardiovascular and respiratory systems is successfully applied in the field of physical education and sports $[35,42]$. In the course of scientific developments, it is expedient to adhere to the provisions of the theory of evaluations [39]. The logic of our research coincided with this provision and included the following stages: the development of scales which help to transform the test results into points; the transformation of the received data into points; calculation of the total points. We performed the development of the evaluation scale on the basis of the application of square deviations, which is confirmed the position of other researchers $[19,26]$. Our approach to the criteria evaluation of the obtained data extends the possibility of interpreting the motor skills testing results of students.

The results of our research confirm that the parameters

Table 1. Average means of the selected criteria for evaluation of the physical and psychophysiological condition of students $(n=75)$

\begin{tabular}{|c|c|c|c|c|c|}
\hline Criterion & $x$ & $\mathrm{~m}$ & Criterion & $\mathrm{X}$ & $\mathrm{m}$ \\
\hline Body mass index (c.u.) & 22.81 & 0.57 & $\begin{array}{l}\text { Duration of the latent period } \\
\text { of choice reaction (ms) }\end{array}$ & 447.54 & 5.14 \\
\hline Power index (\%) & 130.17 & 2.32 & $\begin{array}{l}\text { Level of sensomotor excitation } \\
\text { (ms) }\end{array}$ & 8.63 & 1.42 \\
\hline Index Pynie (c.u.) & 26.3 & 0.84 & $\begin{array}{l}\text { Level of sensomotor accuracy } \\
\text { (ms) }\end{array}$ & 29.23 & 1.09 \\
\hline Speed of running (s) & 14.21 & 0.11 & $\begin{array}{l}\text { Speed of a dominant hand } \\
\text { (times) }\end{array}$ & 7.43 & 0.04 \\
\hline Coordination (s) & 9.87 & 0.04 & $\begin{array}{l}\text { Coefficient of functional } \\
\text { asymmetry (c.u.) }\end{array}$ & 2.94 & 0.11 \\
\hline Power endurance (times) & 37.17 & 1.61 & Loads of thinking (s) & 297.19 & 12.36 \\
\hline Speed power (times) & 39.41 & 0.98 & Potential of CRS (c.u.) & 1.59 & 0.06 \\
\hline Flexibility $(\mathrm{cm})$ & 7.88 & 0.77 & & & \\
\hline
\end{tabular}




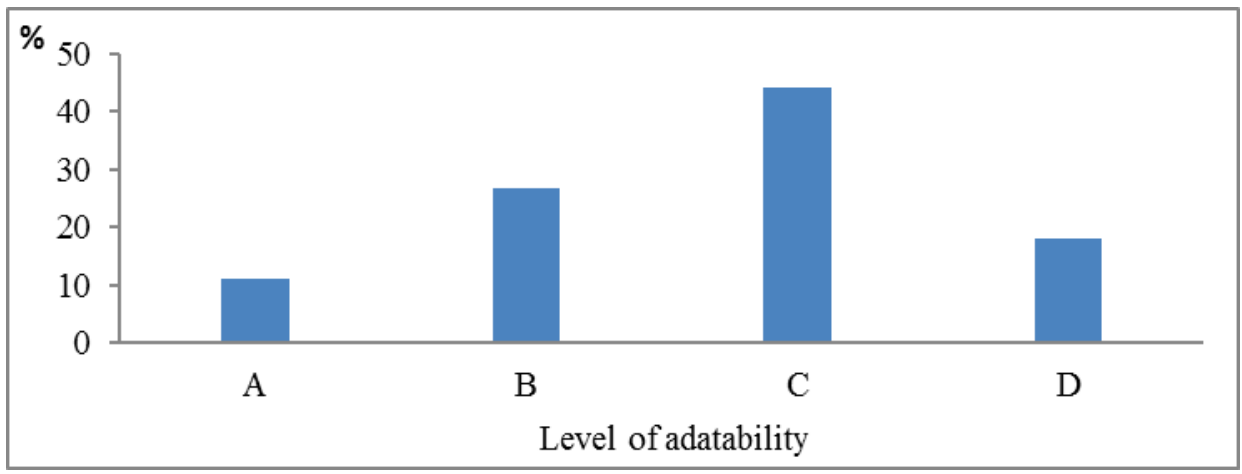

Fig. 1. Percentage of students by degree of adaptability to physical loads $(n=75)$. A - high, $B-$ sufficient, $C-$ insignificant, D - disadaptation

of the physical and psycho-physiological condition of a person objectively characterize the individual peculiarities of students' adaptation to physical loads $[13,38]$. The abovementioned updates existing ideas about the importance of the students' psychomotor system condition evaluation. This allows to determine the student's adaptability to perform various types of motor activity.

It is considered that anthropometric data are an important part of the research and are aimed at determining the somatotype of a person [21,27]. Evaluation of motor qualities must be included in the programs of physical education of students [20-22]. We consider that the complex testing of the psychophysical condition of students should be carried out three times during the study year (incoming, process-current and stage medical and pedagogical control).

It is proved that the implementation of the psychophysiological paradigm provides an opportunity to evaluate objectively the individual peculiarities of the psychomotor system $[11,23,24]$. The authors confirmed that psychomotor quality should be determined by latent periods of the visual-motor reaction; levels of sensorymotor excitation and accuracy; the speed of the left and right hands; coefficient of functional asymmetry, the speed of action. Indicators of the cardiovascular and respiratory systems can objectively characterize the adaptive capacity of the body [35]. The application of the indicator "CRS" complete the evaluation of the student's functional reserve.

We indicated correlations between the indicators of motor qualities and psychomotor system. This is due to the unity of mechanisms of neuro-regulation and psychophysiological support of sensorimotor components of motor activity of students $[11,23]$. In general, we believe that the proposed criteria for assessing the physical and psycho-physiological condition provide an opportunity to determine the degree of adaptation of students to physical loads [38, 41, 43].

The results of our research indicate the need to introduce an individualized evaluation of students' adaptability to physical loads. This is indicated by the number of students who received from 21 to 40 points. These students had "insignificant" degree of adaptability to physical loads.
The obtained data coincide with the results of other studies [44-46]. Thus, in studies of Khotiienko, students of the first year did not have the highest level of physical fitness [46]. The author revealed a low level of $25 \%$ and a lower than average $71 \%$ of students. In our opinion, the given data are overestimated and do not correspond to the national indicators. Similar differences confirm the expediency of individual pedagogical control in the process of physical education; to consider the place of residence; to consider the type of professional loads, gender, age.

The need to consider the individual characteristics of the psychophysical condition of students to confirm the results of other studies [24, 25]. The obtained results confirm the data of studies, which apply the differentiated approach to the organization of physical education [24, 25]. We adhere to the concept that the implementation of a comprehensive, individualized pedagogical control will contribute to the improvement of the educational process in the field of physical culture and sports.

The application of mobile devices to monitor the health condition and motor activity of students will also be useful. This allows them to determine their adaptability to physical loads. Modern services provide the exchange of information about the students' physical condition [27]. Similar methods of self-control significantly increase the motivation of students to physical education. However, it is necessary to consider the possibility of uncontrolled application of gadgets. The application of gadgets can have a negative effect on student health. Therefore, individual-directed pedagogical control will contribute to the optimization of approaches to the application of health-improving technologies.

The advantage of our study is substantiation of the expediency of the introduction of complex individualdirected pedagogical control in physical education. The implementation of the principle of in-depth individualization has a medical and social significance. The basis of this approach is to evaluate the psychomotor qualities of students. It promotes the timely detection and prevention of violations of the psychophysical status of students. The introduction of the author's methodology for determining the students' adaptability degree to physical loads will contribute to improving the physical education organization. 


\section{Conclusions}

The proposed objective criteria of the individual characteristics evaluation of students' physical and psychophysiological condition are acceptable for determining the degree of adaptability of the individual to physical loads. The results of the research conducted have a realistic perspective of implementation in the educational process. The legal and the most appropriate for improving the physical education organization is a comprehensive, individualized pedagogical control. Such an approach considers the peculiarities of physical development and the psycho-physiological condition of students.

\section{Acknowledgment}

The research was carried out in accordance with the topics of the research work of the Department of Biology and Public Health of the State Establishment "South Ukrainian National Pedagogical University named after K. D. Ushynsky": "System adaptation to physical and mental loads in separate stages of human ontogenesis (registration number 0109U000206), "Adaptation of children and youth to educational and physical loads" (registration number 0114U007158).

\section{Conflict of interest}

The author declares that there is no conflict of interest.

\section{References}

1. Cvejic D, Pejovic T, Ostojic S. Evaluation of physical fitness in children and adolescents. Physical Education and Sport; 2013; 11(2), 135-145.

2. Osipov A, Kudryavtsev M, Fedorova P, Serzhanova Z, Panov E, Zakharova L, Savchuk A, Yanova M, Zhavner T, Klimuk Y. Components of positive impact of exposure on university physical culture and sports on students' physical loads. Journal of Physical Education and Sport, 2017; 2: 871-878. https://doi.org/10.7752/jpes.2017.02133

3. Platonov V. Theories of adaptation and functional systems in the development of knowledge in the field of preparation of athletes. Science in Olympic Sport, 2007; 1: 29-45.

4. Samokish I, Bosenko A, Dishel' G. Optimization of teaching physical education at higher educational institutions on the basis of students' functional capacity monitoring. Nauka $i$ osvita, 2016; 8: 151-157.

5. Manolachi V, Budevici-Puiu L. The insurance and evaluation of the scientific research quality within the institution of higher education of physical training and sport from republic of Moldova. Quality - Access to Success, 2016; 17(150): 6567.

6. KatzmarzykPT,LeeIM,MartinCK,BlairSN.Epidemiology of Physical Loads and Exercise Training in the United Conditions. Progress in Cardiovascular Diseases. 2017;60(1):3-10. https://doi.org/10.1016/j.pcad.2017.01.004

7. Santana CCA, Azevedo LB, Cattuzzo MT, Hill JO, Andrade LP, Prado WL. Physical fitness and academic performance in youth: A systematic review. Scandinavian Journal of Medicine \& Science in Sports. 2017;27(6):579-603. https://doi.org/10.1111/sms.12773

8. Gerber M, Ludyga S, Mucke M, Colledge F, Brand S, Puhse U. Low vigorous physical loads is associated with increased adrenocortical reloads to psychosocial stress in students with high stress perceptions. Psychoneuroendocrinology. 2017;80:104-113. https://doi.org/10.1016/j.psyneuen.2017.03.004

9. Hollis JL, Sutherland R, Williams AJ, Campbell E, Nathan $\mathrm{N}$, Wolfenden $\mathrm{L}$, et al. A systematic review and meta-analysis of moderate-to-vigorous physical loads levels in secondary school physical education lessons. International Journal of Behavioral Nutrition and Physical Loads. 2017;14. https://doi.org/10.1186/s12966-017-0504-0

10.Kenney EL, Gortmaker SL. United Conditions Adolescents' Television, Computer, Videogame, Smartphone, and Tablet Use: Associations with Sugary Drinks, Sleep, Physical Loads, and Obesity. Journal of Pediatrics. 2017;182:144-149. https://doi.org/10.1016/j.jpeds.2016.11.015
11.Il'in E. Differential psychophysiology. Sankt Petersburg: Peter; 2005. (in Russian)

12.Nikandrov V. Psychomotor system. Sankt Petersburg: Speech; 2014. (in Russian)

13.Degtiarenko T, Yagotin R. Expediency of assessing students' adaptive capacity and psychosomatic health according to objective physiological parameters. Nauka i osvita, 2017; 8: 66-71. DOI: 10.24195/2414-4665-2017-8-9 (in Ukrainian)

14.Bang KS, Lee I, Kim S, Lim CS, Joh HK, Park BJ, et al. The Effects of a Campus Forest-Walking Program on Undergraduate and Graduate Students' Physical and Psychological Health. International Journal of Environmental Research and Public Health. 2017;14(7). https://doi.org/10.3390/ijerph14070728

15.Blake H, Stanulewicz N, McGill F. Predictors of physical loads and barriers to exercise in nursing and medical students. Journal of Advanced Nursing. 2017;73(4):917-929. https://doi.org/10.1111/jan.13181

16.Pyky R, Koivumaa-Honkanen H, Leinonen AM, Ahola $\mathrm{R}$, Hirvonen $\mathrm{N}$, Enwald $\mathrm{H}$, et al. Effect of tailored, gamified, mobile physical loads intervention on life satisfaction and self-rated health in young adolescent men: A population-based, randomized controlled trial (MOPO study). Computers in Human Behavior. 2017;72:13-22. https://doi.org/10.1016/j.chb.2017.02.032

17.Podstawski R, Markowski P, Choszcz D, Lipinski A, Boryslawski K. Effectiveness of martial arts training vs. other types of physical loads: differences in body height, body mass, BMI and motor abilities. South African Journal for Research in Sport Physical Education and Recreation. 2017;39(1):111-133.

18.Siqueira JCF, da Silva LB, Coutinho AS, Rodrigues RM. Analysis of air temperature changes on blood pressure and heart rate and performance of undergraduate students. Work-a Journal of Prevention Evaluation \& Rehabilitation. 2017;57(1):43-54. https://doi.org/10.3233/wor-172533

19. Sergiienko L, Sharij D. Methodological bases of complex tests in physical education and sport. Teoriia ta metodika fizichnogo vikhovannia, 2010; 5: 3-12. (in Ukrainian)

20.Krucevich T. Sainchuk M. Pidletejchuk R. Consequences of the destruction of physical fitness structure in the architectonics of the subject physical culture. Teoriia $i$ metodika fizichnogo vikhovannia $i$ sportu, 2018; 2: 102-109. (in Ukrainian) DOI: https://doi.org/10.32652/ tmfvs.2018.2.102-109

21.Furman Iu, Miroshnichenko V, Drachuk S. Perspective models of physical culture and health technologies in physical 
education of students of higher educational establishments. Kiev; 2013. (in Ukraine)

22.Sergiienko VM. The system of motor abilities control of student youth: the theory and methodology of physical education. Sumy: Sumy Condition University; 2015. (in Ukrainian)

23.Degtiarenko T. Relationship between the indicators of the degree of impairment perceptual- cognitive and psychomotor functions. Eksperimental'na i klinichna medicina, 2016; 2(71): 69-72. (in Ukraine)

24.Tarovyk N, Korobeynikov G, Dudnik A, Vrzhesnevskaya G. Dynamics of the Psychophysiological Condition of Teenagers with Different Levels of Motor Loads, Ukrainian Journal of Medicine, Biology and Sport, 2017; 6(9): 119-125. https:// doi.org/10.26693/jmbs02.07.119

25.Korobejnikov G, Korobejnikova L, Shackikh V. On-going evaluation of the functional condition of highly skilled wrestlers in the training process. Nauka volimpijskom sporte, 2016; 4:72-77. (in Ukrainian)

26.Blavt $\mathrm{O}$. The effectiveness of the practical implementation of the provisions of the concept of reproduction technology the test control on the condition of physical preparedness of students' in special medical groups. Naukovij chasopis NPU imeni M. P Dragomanova, 2015; 11(66): 22-25. (in Ukrainian)

27.Eberline A, Ricards A. Teaching with Technology in Physical Education. A Journal for Physical and Sport Educators, 2013; 26(6): 38-39. https://doi.org/10.1080/08924562.2013.839522

28.Palicka P, Jakubec L, Zvonicek J. Mobile apps that support physical activities and the potential of these applications in physical education at school. Journal of human sport \& exercise, 2016; 11: 176-194. https://doi.org/10.14198/jhse.2016.11.Proc1.08

29. Santos I, Sniehotta FF, Marques MM, Carraca EV, Teixeira PJ. Prevalence of personal weight control attempts in adults: a systematic review and metaanalysis. Obesity Reviews. 2017;18(1):32-50. https://doi.org/10.1111/obr.12466

30.Furman A. Psychodiagnostics of personal adaptability. Ternopil: Economic Thought; 2013. (in Ukrainian)

31.Kapkan O, Khudolii O, Bartik P. Pattern Recognition: Physical Exercises Modes During Motor Skills Development in Girls Aged 14. Teoriâ Ta Metodika Fìzičnogo Vihovannâ, 2018;18(4): 167-174. https://doi.org/10.17309/tmfv.2018.4.02

32.JavedA, JumeanM,MuradMH,OkoroduduD, KumarS, Somers VK, Sochor O, Lopez-Jimenez F. Diagnostic performance of body mass index to identify obesity as defined by body adiposity in children and adolescents: a systematic review and meta-analysis. Pediatric Obes. 2015; 10(3):234-244. https://doi.org/10.1111/ijpo.242

33. Bradbury KE, Guo W, Cairns BJ, Armstrong MEG, Key TJ. Association between physical loads and body fat percentage, with adjustment for BMI: a large crossectional analysis of UK Biobank. J Neurointerv Surg, 2017; 7(3):1-9. https://doi.org/10.1136/bmjopen-2016-011843

34.Sergiienko L. Sports metrology. Kiev: KNT; 2010. (in Ukrainian)

35. Bosenko A. Biological methods of research in physical education and sports. Odessa; 2016. (in Ukrainian)

36. Ayers S, High School Students' Physical Education Conceptual Knowledge. Research quarterly for exercise and sport, 2004; 75(3): 272-287. https://doi.org/10.1080/02701367.2004.10609160

37.Mantrova I. Methodical guide on psychophysiological and psychological diagnosis. Ivanovo: Neurosoft; 2007. (in Russian)

38.Iagotin R, Dehtiarenko T, Bosenko A. Complex Examination of University Students' Psychosomatic Health. Ukrainian Journal of Medicine biology and sports, 2017; 4(6): 223-228. https://doi.org/10.26693/jmbs02.04.223

39.Godik M. Sports metrology. Moscow: Physical Culture and Sport; 1988. (in Russian)

40.Sutula V. Peculiarities of the use of statistical methods in scientifi c research in the fi eld of physical culture and sports. Teoriia i metodika fizichnogo vikhovannia i sportu, 2014; 1, 82-86. (in Ukrainian)

41.Iagotin R. Determination of personal adaptation to physical loads within the context of implementation of individualoriented pedagogical control. Naukovij visnik PNPU imeni K. D. Ushins'kogo,2018; 3(122): 109-114. (in Ukrainian)

42.Osipov A, Vonog V, Prokhorova O, Zhavner T. Student learning in physical education in Russia (problems and development perspectives). Journal of Physical Education and Sport, 2016; 1 (Supplement issue): 688-693. https://doi.org/10.7752/jpes.2016.s1111

43.Daly M, Ahlborg H, Ringsberg K, Gardsell P, Sernbo I. Association between changes in habitual physical loads and changes in bone density, muscle strength, and functional performance in elderly men and women. J Am Geriatr Soc, 2008; 56 (12): 2252-2260. https://doi.org/10.1111/j.1532-5415.20 08.02039.x

44.Dukh T, Bodnar I, Dunec'-Les'ko A, Pavlos' O, Lemeshko V. Physical loads and motivational orientation of student youth for physical education classes. Pedagogichni nauki: teoriia, istoriia, innovacijni tekhnologii, 2018; 3(77): 67-77. https://doi.org/10.24139/2312-5993/2018.03/067-077

45.Mishchenko O, Sitnik R. Investigate of level the physical readiness of students of the Sumy Condition Pedagogical University named after A.S. Makarenko. Teoriia ta metodika fizichnogo vikhovannia, 2008; 05(43): 47-50. (in Ukrainian)

46.Khotiienko S. Research and analysis of the level of physical preparedness of Oles Honchar Dnipro National University students. Slobozhans'kij naukovo-sportivnij visnik, 2018; 1(64): 108-11. https://doi.org/10.15391/snsv.2018-1.019. (in Ukrainian) 


\section{Information about the authors:}

Yagotin R.S.; (Corresponding Author); http://orcid.org/0000-0002-8342-5156; iagotin.rodion@gmail.com; Odessa National Academy of Food Technology; Kanatnaya st., 112, Odessa, 65001, Ukraine.

Degtyarenko T.V.; https://orcid.org/0000-0003-4462-8863; matanya@ukr.net; South Ukrainian National Pedagogical University named after K. D. Ushynsky; Staroportofrankivs`ka St. 26, Odessa, 65020, Ukraine.

Bosenko A. I.; http://orcid.org/0000-0003-3472-0412; bosenco@ukr.net; South Ukrainian National Pedagogical University named after K. D. Ushynsky; Staroportofrankivs`ka St. 26, Odessa, 65020, Ukraine.

Plisko V. I.; https://orcid.org/0000-0001-8714-985X; rost0279@gmail.com; National University of «Chernihiv Collegium» Taras Shevchenko ; Hetman Polubotka street, 53, Chernihiv, 14013, Ukraine.

Dolinsky B. T.; https://orcid.org/0000-0002-3745-2460; dolinskiy58@ukr.net; South Ukrainian National Pedagogical University named after K. D. Ushynsky; Staroportofrankivs`ka St. 26, Odessa, 65020, Ukraine.

\section{Cite this article as:}

Yagotin RS, Degtyarenko TV, Bosenko Al, Plisko VI, Dolinsky BT. Criterion score of the physical and psychophysiological condition of students in the context of determining their individual adaptability to physical loads. Physical education of students, 2019;23(1):51-57.

https://doi.org/10.15561/20755279.2019.0108

The electronic version of this article is the complete one and can be found online at: https://sportedu.org.ua/index.php/PES/issue/archive

This is an Open Access article distributed under the terms of the Creative Commons Attribution License, which permits unrestricted use, distribution, and reproduction in any medium, provided the original work is properly cited http://creativecommons.org/licenses/by/4.0/deed.en

Received: 11.01.2019

Accepted: 10.02.2019; Published: 28.02.2019 